\title{
$\begin{array}{ll}\text { Research Square } & \text { Preprints are preliminary reports that have not undergone peer review. } \\ \text { They should not be considered conclusive, used to inform clinical practice, }\end{array}$
}

\section{Clinical Determinants of Disease Progression in Patients with Beta- sarcoglycan Gene Mutations.}

\author{
Giulia Marchetti \\ IRCCS Foundation Maggiore Policlinico Hospital: Fondazione IRCCS Ca' Granda Ospedale Maggiore Policlinico \\ Luca Valenti \\ University of Milan: Universita degli Studi di Milano \\ Yvan Torrente ( $\nabla$ yvan.torrente@unimi.it) \\ University of Milan: Universita degli Studi di Milano https://orcid.org/0000-0002-2705-3984
}

\section{Research}

Keywords: Limb Girdle Muscular Dystrophy 2E (LGMD 2E), LGMDR4, natural history, creatine kinase (CK), ejection fraction (EF), pulmonary function test (PFT) measures

Posted Date: December 16th, 2020

DOI: https://doi.org/10.21203/rs.3.rs-127302/v1

License: 두 (i) This work is licensed under a Creative Commons Attribution 4.0 International License. Read Full License 


\section{Abstract}

Background: Limb Girdle Muscular Dystrophy 2E (LGMD 2E), recently renamed as autosomal recessive limb-girdle muscular dystrophy-4 (LGMDR4), is characterized by the lack of beta-sarcoglycan, normally expressed in skeletal muscles and cardiomyocytes. We hypothesized that progressive respiratory and left ventricular (LV) failure in LGMDR4 could be associated to the age and interrelated phenomena of disease's natural history.

Methods: We conducted a retrospective review of the records of 26 patients with LGMDR4. Our primary objective was to compare the rates of decline among creatine phosphokinase (CPK) values, pulmonary function test (PFT) measures, and echocardiographic estimates and to relate them to patients' age.

Results: The rates of decline/year of CPK, PFTs and LV function estimates are significatively bound to age, with the LV ejection fraction (EF) being the strongest independent variable describing disease progression. Moreover, the rate of decline of CPK, PFTs and LV differed in patients grouped according to their genetic mutations, demonstrating a possible genotype-phenotype correlation. The parallel trend of decline in CPK, PFTs and EF values demonstrates the presence in LGMDR4 of a simultaneous and progressive deterioration in muscular, respiratory, and cardiac function.

Conclusions: This study expands the current knowledge regarding the trend of CPK values and cardiac and respiratory impairment in patients with LGMDR4, to optimize the monitoring of these patients, to improve their quality of life and provide clinical indices capable of quantifying the effects of any new gene or drug therapy.

\section{Background}

Limb Girdle Muscular Dystrophy 2E (LGMD 2E), recently re-classified as Limb Girdle Muscular Dystrophy Recessive type 4 (LGMDR4) [1], is a rare type of recessive muscular dystrophy caused by the lack of beta-sarcoglycan. Sarcoglycans (SG) are a group of four transmembrane proteins: alpha (a-), beta (b-), gamma (c-), and delta-sarcoglycan (d-SG), organized in a tetramer that stabilizes the dystrophin-associated glycoprotein complex [2]. These proteins are expressed in the sarcolemma of smooth and striated muscular fibers. Bi-allelic mutations in the genes of each sarcoglycan cause specific subtypes of recessive LGMD: mutation on the a-SG's gene (SGCA) leads to the LGMDR3, on the bSG's (SGCB) to the LGMDR4, on the c-SG's (SGCC) to the LGMDR5 [3], while mutations on the d-SG's have been discovered as the cause of an extremely rare type of LGMD: LGMDR6 [4]. The four SG assemble during a stepwise process, that mainly depends on b-SG, which initiates the assembly and whose association with d-SG is fundamental for the correct localization of the whole complex in the membrane [5]. Different roles of SG partially explain the wide differences in clinical phenotypes among sarcoglycanopathies: age of onset, disease progression, muscle, joint, cardiac, and respiratory involvement can vary greatly. Because of its fundamental role, the lack of b-SG causes a severe form of muscular dystrophy, which debuts with a progressive weakening of proximal muscles in early childhood [6]. The presence of respiratory and heart disfunction in LGMDR4 patients makes this disease close to Duchenne Muscular Dystrophy, although the pathophysiology of cardiac anomalies might be different [7]. More than $60 \%$ of LGMDR4 patients suffer from dilated cardiomyopathy [8], a condition that is less frequently observed in LGMDR3 and LGMDR5[9]. Also, LGMDR4 is frequently associated with respiratory failure[10], a leading cause of death in affected individuals that is nowadays successfully prevented using non-invasive ventilation (NIV) with a demonstrated gain in survival [11]. Aside from this little information, the natural history of LGMDR4 is still poorly known because of its rareness (prevalence is estimated around $0.86 \times 10^{-6}$ individuals) and because of the great difficulties in collecting data from so few and scattered patients. In literature, studies on LGMDR4 patients mainly consider outcome measures based on the motor function of lower and upper limbs [12]. Nonetheless, the evaluation of lung function and respiratory muscle activity should not be underestimated in monitoring disease progression and to identify early signs of ventilatory insufficiency, to plan optimal interventions for improving the quality of life and to quantify the effects of new genemodifying and pharmacological therapeutic strategies $[13,14]$. A recent study by J. Manera Diaz et al. [15] established independent risk factors associated with loss of ambulation before 18 years of age for sarcoglycanopathies based on the onset of symptoms during the first decade of life and protein expression in muscle biopsy lower than $30 \%$. Therefore, there is still little knowledge to predict the development of cardiac and respiratory involvement in LGMDR4 patients. Several reports suggested that $>50 \%$ of patients developed cardiac and respiratory problems [10;16] although recently Winckler et al. [17] described the frequency of cardio-respiratory involvement to be $<5 \%$ in sarcoglycan patients. To better characterize the cardiac and respiratory muscle involvement in LGMDR4 patients, we collected demographic, genetic and clinical data from an Italian cohort of patients with mutations in the beta-sarcoglycan gene.

\section{Materials And Methods}

\section{Aims.}


In this study we investigated the possible association between progressive respiratory and LV failure could be associated to the age in LGMDR4 and their connection to interrelated phenomena of disease's natural history. Specific aims were to study the evolution of CPK levels and cardiac and respiratory functions in terms of spirometry and echocardiography pattern from childhood to adulthood, to identify possible key points in the natural course of the disease and to improve the given treatments. Furthermore, we evaluated the strength of a possible genotype-phenotype correlation.

\section{Design.}

This study was designed as a 10-year observational retrospective study collecting clinical and genetic data from 26 patients with a defined genetic diagnosis of LGMDR4. To gain a better knowledge of the natural history of this uncommon condition we highlighted significative correlation between CPK, cardio-respiratory assessments and disease progression over years. Interconnection between variables was evaluated in all patients and after stratification by presence or absence of a common genetic mutation in exon 3 previously described as causative of a severe phenotype $[4 ; 18]$.

\section{Patients.}

26 patients, with a defined genetic diagnosis of LGMDR4 were enrolled, ranging in age from 8 to 55 years and with data collected on at least three different visits. Patients were enrolled within the "Gruppo Familiari Beta-sarcoglicanopatie" Italian network and evaluated in different Italian centres once or twice per year, for a total of 542 visits (which includes 216 neurological, 177 cardiological and 149 pneumological examinations). All patients or parents signed a consent form, approved by the local ethics committee according to the declaration of Helsinki. The study was approved by the Ethics Committee of the Fondazione IRCCS Ca' Granda Ospedale Policlinico of Milan (EC approval 386_2020, 19 May 2020) and registered on ClinicalTrials.gov with the following number: NCT04509609.

\section{Clinical Tests.}

All clinical data were provided by patients, on paper or informatic supports. Data were collected in a table, purposely created. We started recording genetic, histological and immunohistochemical tests that led to diagnosis. Beside these, also diagnosis related information such as age at onset and/or at diagnosis, first symptoms and family history were considered. Every neurological, cardiological and pulmonological examinations performed through the years were reported. Functional, blood and laboratory tests were included too. Each data that could help determining the disease's evolution was collected. If present, we reported any sign defining muscular involvement: hypotrophy, pseudohypertrophy, weakening grade and distribution, ability to stand on toe, dysphagia, scapular winging, spinal deformity and so on. Also, any kind of muscular function assessment done through the years was recorded. Often patients followed in different hospitals underwent different evaluations, all were collected on the off chance to find the one which best describes muscle impairment. Respiratory disfunction was assessed by spirometry and overnight oximetry. Pulmonary function test variables (expressed as percentage of predicted) consisting of Vital Capacity (VC), Forced Vital Capacity (FVC), Forced Expiratory Volume in first second (FEV1) were included in the study analyses. Also, we reported ventilatory and cough parameters: Maximal Voluntary Ventilation (MVV), Maximal Inspiratory Pressure (MIP), Maximal Expiratory Pressure (MEP). Ejection fraction (EF) data were collected from the echocardiogram reports.

\section{Statistical Analysis.}

We ordered each clinical variable available according to patients' age. Not for every variable and not for every patient we obtain enough data to have a significant description of the natural history of the disease. Otherwise, for some variables we were able to describe a life-time trend. As it has been recently demonstrated that patients with truncating mutations, and therefore lower proteins' concentrations, may show a more severe clinical progression [15] and in view of our preliminary observations, in order to highlight any possible genotype-phenotype correlation, patients were analysed both as total and as grouped in two genetic subgroups: group A, for patients carrying in homozygosis or in compound heterozygosis a specific truncating mutation in exon 3 (c.377_384dupICAGTAGGA), which is known to cause severe disease [4;18], and group $B$ for patients with every other kind of alteration. In our cluster of patient variants were found in exon 3, exon 4 , exon 6 and exon 1 , which is known for causing a mild subtype of LGMDR4 [18]. 12 patients were included in group A ( 6 men and 6 women, median age 25 years) and 14 patients were included in group B (6 men and 7 women, median age 32$)$. At first, we ordered data according to age, both for the overall cohort and for the genetic subgroups. This enabled us to improve data samples for each age and to compare disease progression between groups.

Our first aim was to examine the trend of clinical variables over the years, both in the overall cohort and in patients stratified by genotype. We created for each variable a graph with on $\mathrm{X}$ axis the age of patients and on $\mathrm{Y}$ axis the values of each variables. We also explore the possible 
correlation of available variables with clinically significative events. As not every patient underwent yearly a clinical evaluation and provided reliable clinical charts, we considered objective events as clinical outcomes; those were namely: age of loss of ambulation, age of introduction of drug therapy to support cardiac function and age of introduction of respiratory support. Analyses were performed using generalized linear models: linear regression models were fit to analyse continuous traits, with dependent variables such as CPK, EF, VC, FVC and FEV1. To assess the major independent predictors of clinically relevant outcomes, models were adjusted for confounding factors, as specified in the results section. Variables with skewed distributions were logarithmically transformed before to be entered the models. For all the analysis we considered every data available and grouped them for age of observation, independently from patient identity. Statistical analyses were carried out using the JMP 12.0 (SAS Institute, Cary, NC, USA). P-values $<0.05$ were considered statistically significant.

\section{Results}

26 patients (age range 8-55) were included in the study. Each year each patient underwent on average 1.2 neurological visit, 1.5 cardiological visits, 1.3 pneumological visits and 5.1 laboratory tests. The mean of the total reported evaluations was 14 for neurological visits (range $3-$ 30), 11.8 for cardiological ones (range 3-16), 11.5 for pneumological ones (range 3-32) and 25.3 for laboratory tests (range, 2-112). The median time interval between the first and the last visit was 2.8 years in patients with more than one evaluation. For patients who underwent multiple visits, mean time between the first and the last visits was 15.2 years for neurological assessments (range 2-30), 14.5 for cardiological ones (range 1-37), 12.5 for pneumological ones (range 2-27) and 16.7 for laboratory tests (range 1-41). 5 patients received steroids, 14 were assuming drugs to ameliorate heart work and 11 were using devices to support respiratory function; 1 patient underwent cardiac transplant. 20 participants were non ambulatory. We observed a consistent and significant decrease in all biomarkers evaluated (including CPK, EF, VC, FVC, FEV1) with ageing (Tab. 1, left panel). Below we comment on the trends in disease's biomarkers in the whole cohort and in subgroups. CPK values' assessments showed a significant decreasing trend over the years ( $p$ value 8,30E-10; Table 1). This was not surprising since muscle mass decreases as the disease progresses (Figure 1.A). Interestingly, group A patients showed a constant decrease in CPK values (line slope was -907.52; Figure 1.A and Table 2) with a significant regression according to age ( $\mathrm{p}$ value of 2E-13) (Table 2), whereas patients in group $B$ the CPK values were more stable and the regression was less significant with age (line slope -344.96; $p$ value 2.8E-4) (Table 2), with the only exception of one peak observed at 12 years in one patient (Figure 1.A). The univariate analysis of EF evolution according to age showed a significant decreasing trend in all the patients (Figure 1.B) ( $p$ value 0,0023; Table 1). Notably, difference appears between decreasing trends of EF in groups A and B (Figure 1.B) with a severe decrease in few years for group A's patients (line slope -0.99; Table 2). Patients belonging to group $B$ also suffered from cardiac impairment, which still seemed to follow a slower progression (line slope -0.39; Table 2). In both groups, we observed a significative relation to age (in group A p value $=0.03$, in group B p value $=0.001$; Table 2). It is important to notice that in group B we collected data from the elder patient that at age of 50 still preserved a good left ventricle function (EF 50\%) compared to the younger patient in group A who at early 20 already suffered from a severe cardiac dysfunction (EF $25 \%$ ). Both patients assume beta-blocker to prevent heart failure and cardiovascular events. Spirometry values were considered as percentages of the predicted value according to age, sex, and height. FEV1 (Figure 1.C), FVC (Figure 1.D), VC (Figure 1.E), and were significantly related to age in the overall cohort analysis (VC $p$ value $=0,0002$, FVC $p$ value $=2,42 E-06$, FEV1\% $p$ value $=5,96 E-09 ;$ Table 1 ). A significative trend for all these 3 variables was observed in patients of group A (VC p value= 2.1E-3, FVC p value= 5E-10, FEV1\% p value =3 E-10; Table 2). In group B, the univariate analysis was statistically significative only for VC ( $p$ value $=5.7 E-7)$ and FEV1\% $(p$ value $=1.1 E-2)($ Table 2$)$. Interestingly, VC reduction is remarkably different between mutation groups. Along with all spirometry values, VC decreases more rapidly in group $A$ than $B$ in the range of age of 6-12 years-old (line slope for group A 3.56, for group B 1.85) (Table 2). In addition, there was no difference in VC between groups at 12 years old (mean value $77.25 \%$ in group A, 76.5\% in group B) but at 18 years old group A's had decreased more significantly (mean value $43.33 \%$ in group A versus $59.5 \%$ in group B) (Figure 1). Similarly, FVC showed a significant lowering rate in group A versus group $B$ (line slope for group $A=3.56$ and for group $B=1.12$; Table 2 ) with a mean value at 12 years old, $60.44 \%$, for group $A$ and $81 \%$ for group $B$ (Figure 1.D). Furthermore, also FEV1 values at 12 years-old reported the same differences between groups described for VC and FVC (mean value of $68.4 \%$ for group $A$ and $83.5 \%$ for group B) and its variation over years differs between groups in a significant manner (mean value at 22 years-old of $37.67 \%$ for group $A$ and $59.5 \%$ for group $B$ ). These differences were related to the FEV1 line slope of group $A$ and group $B$ (-3.55 in group A and -1.64 in group B) (Table 2). We then investigated the correlation between studied variables (Table 3 ). We found a significant pairwise correlation in all combinations of variables except for two couples: EF and CPK, and FVC and VC (Table 3 ). We further studied variables connection, both with paired correlation analysis and with multivariate generalized linear models. As mentioned above, the paired correlation analyses preliminary demonstrated the independence of CPK to EF. This data was confirmed by multivariate models. These models were created to test which of the considered markers is more strongly associated to disease progression over the years. Our interest was to evaluate whether parameters of cardiac and respiratory function correlate with disease progression independently of CPK, whose decrease could reflect the reduction in muscle mass. We found that both FEV1 ( $p=0.0021)$ and EF ( $p=0.0019)$ significantly lower with disease progression, regardless of CPK (Table 1, models 1 and 2). In a subset of 16 patients (9 from group A and 7 from group B) for whom all these variables were available, we found that EF was the strongest independent marker of disease progression ( $p=0.0201$, Table 1, model 3). Finally, in an exploratory analysis conducted in a subset of patients for whom at least two observations were available, we tested whether the 
trend of disease biomarkers over years/disease progression can predict the age of development of clinical events - disability (Table S1). Interestingly, we found a significant association between the rate of decrease in CPK and the age of introduction of respiratory support $(p=0.0009)$. A non-significant trend was also observed between the FVC and the age of ambulation loss $(p=0.078)(T a b l e ~ S 1)$.

\section{Discussion}

In this study we reported retrospective data of 26 patients diagnosed with LGMDR4. We stratified patients according to their genetic diagnosis to evaluate the impact of the genetic background on the disease natural history. Because of the rareness of this condition and of differences in the follow up routine between hospitals, data collection was very heterogeneous in terms of both the type and frequency of clinical evaluation. Still, among clinical variables analysed, some showed a clear trend over time that could help to better describe the natural history of the disease. CPK, EF and spirometry values (VC, FVC, FEV1) can help to assess the LGMDR4 evolution. Particularly CPK greatly change in a lifetime: its peak is seen around 3 years old when first muscular injury symptoms appear; its values show a clear decrease after the age of 11-13 years old, when most patients of our cluster lost ambulation (mean age of loss of ambulation is 17 years old, median age is 13, range 8-46). Group A patients demonstrated to have a faster reduction of enzymes values than those in group B. Further, although in both groups CPK was significantly related to age, this correlation was much tighter for group A ( $p=2 E-13$; Table 2), probably in reason of their more severe clinical phenotype. In our analysis, we confirmed that CPK predicts muscular damage evolution, highlighting the importance of periodic CPK assays as previously described for others muscular dystrophies [12]. Notably, a steeper rate of decrease in CPK is linked to a younger age of need for respiratory support, as a turning point in the natural history of LGMDR4 (Table S1).

In line with CPK trend, the decline of VC, FVC and FEV1 values were consistent with the progressive nature of LGMDR4 and generally with the type of respiratory impairment affecting neuromuscular patients; $\mathrm{VC}$ has always been considered the first marker of inspiratory muscle weakness and the lowering of lung compliance in these patients [19], and FVC and FEV1 are known as important markers of neuromuscular diseases progression [20]. Notably, in our cluster both FVC and FEV1 showed a faster reduction than VC. These data, although unexpected, can be explained as FVC and FEV1 are tightly related to both the expiratory and the inspiratory accessory muscles, which include the muscles of the upper girdle [21] whereas VC is only partly dependent on muscular function as largest part of inspiratory work is done by rib cage compliance. Moreover, the absence of correlation between VC and FVC highlights differences between these variables.

Overall, spirometry variables were independent of the rate of CPK decline and can therefore be eligible to monitor disease evolution. Based on the present data, the FVC decline may accurately predict the age at loss of ambulation ( $p=7,83 \mathrm{E}-02)$. Only for FEV1 we have enough data prior 11 years old to consent us to observe the relative steadiness of this value before this age when most severe patients have lost the ability to walk. Unfortunately, because of intrinsic difficulties of the test itself, spirometry can hardly be done before 10 years old. Nevertheless, it might be important to impose this kind of examination to LGMDR4 patients even in early childhood to gain more knowledge about early respiratory impairment and its pathogenic mechanisms. Particular attention might be payed to FEV1 and FVC, which have already proven reliable in children under the age of 8 [22] and are significantly related to mortality in neuromuscular diseases [23]. All spirometry variables showed a greater reduction rate in group A compared to group B (Table 3). In group A all three of them had a significant relation to age, while in group B only VC and FEV1 were significantly age-related (Table 3). It is important to notice that spirometry seems to be rarely performed by group B patients, probably because of the relative benignity of their conditions. The scarceness of data surely affects the reliability of these results.

Our results provide insight into the relevance of EF decrease with aging in the studied cohort. Indeed, we observed a $4.5 \pm 1.4 \%$ decrease per year in patients for whom this information was available, which was larger than the decrease in FEV1 $(-1.9 \pm 0.3 \%)$ and FVC $(-1.7 \pm 0.3 \%)$ per year. Most importantly, the association between EF's decline and disease's progression was independent of the rate of decrease in CPK and FEV1 (Table 3), suggesting that the EF could be a good candidate marker for estimating LGMDR4 progression regardless of therapy and its use should be implemented throughout patients' life to predict and prevent heart failure and cardiovascular events.

Concerning the impact of the genetic background, all group A's patients have at least one truncating mutation which has already been demonstrated to relate to a more severe phenotype [15]. Consistently with these data, all patients in group A lost ambulation in early teens or even before and, investigating differences between mutation groups, we observed homogeneity in patient of group A which showed a steeper decline in the variables CPK, EF, VC, FVC and FEV1. However, the number of clinical data and evaluations was higher in group A than group B, thus limiting our comparisons. This is likely due to the milder clinical presentation of group B patients, requiring a less close follow up routine. Limitations of this study include the small sample size determined by the rarity of LGMDR4 and differences in follow-up routines between clinical sites. Moreover, in the case of muscle function involvement, we only collected data regarding age of losing ambulation. Future studies analyzing a large cohort of patients would be useful to confirm our observation. However, the data presented here are still relevant because they can help in the design of clinical trial in LGMDR4 to determine the effectiveness of the therapy. 


\section{Conclusions}

We studied the evolution over time of common variables that can be measured multiple times over the course of a structured follow-up for LGMDR4. Both respiratory and cardiac function show a significant decrease over the years. The worsening of muscle function is faithfully described by the decrease in CPK, which has proven to be not only the simplest and less expensive parameter to closely follow the progression of the disease but also to predict other clinical outcomes, such as the need to introduce respiratory support. Among respiratory variables, VC, FVC, and FEV1 were significantly correlated with age, suggesting a decrease in respiratory muscle compliance [15;18]. In addition, EF was the biomarker that most steadily decreases with ageing and disease progression. Finally, we confirmed the existence of a phenotype-genotype correlation, noting a considerably more severe muscle damage and therefore a worse disease course in patients with the truncating mutation c.377_384dupICAGTAGGA on exon 3, both in homozygosis and heterozygosis.

\section{Abbreviations}

$\mathrm{CPK}=$ Creatine Phosphokinase

$E F=$ ejection fraction

FVC= Forced Vital Capacity, considered as percentage of predicted

FEV1 $=$ Forced Expiratory Volume in the first second considered as percentage of predicted

LGMD 2E= Limb Girdle Muscular Dystrophy 2E

LGMDR3= Limb Girdle Muscular Dystrophy Recessive type 3

LGMDR4= Limb Girdle Muscular Dystrophy Recessive type 4

LGMDR5= Limb Girdle Muscular Dystrophy Recessive type 5

LGMDR6= Limb Girdle Muscular Dystrophy Recessive type 6

$\mathrm{LV}=$ Left Ventricle

MEP $=$ Maximal Expiratory Pressure

MIP = Maximal Inspiratory Pressure

MVV = Maximal Voluntary Ventilation

NIV = Non-Invasive Ventilation

PFT = Pulmonary Function Test

$S G=$ Sarcoglycans

VC= Vital Capacity, considered as percentage of predicted

\section{Declarations}

\section{Authors' contributions:}

G.B. Marchetti: Investigation, writing original drafts; L. Valenti: supervision, statistical analysis, writing review and editing; Y. Torrente: conceptualization, supervision, writing review and editing

\section{Conflicts of interest/Competing interests:}

all authors report no disclosures relevant to the manuscript.

\section{Ethics approval:}




\section{Consent to participate:}

written informed consent was collected from the patient for the inclusion of deidentified clinical data in a scientific publication, in accordance with the Declaration of Helsinki.

\section{Availability of data and material:}

deidentified data and material inherent to the case report and not included in the manuscript are available on request to the corresponding author by any qualified investigator.

\section{Study Funding:}

this research was funded by Gruppo Familiari Beta-sarcoglicanopatie Onlus. Funder of the study had no role in study design, data analysis, data interpretation, or writing of the report.

\section{Acknowledgements:}

not applicable.

\section{References}

1. Straub V, Murphy A, Udd B. LGMD workshop study group. 229th ENMC international workshop: Limb girdle muscular dystrophies Nomenclature and reformed classification Naarden, the Netherlands, 17-19 March 2017. Neuromuscul Disord. 2018 Aug;28(8):702710. doi: 10.1016/j.nmd.2018.05.007. Epub 2018 May 24. PMID: 30055862.

2. Ozawa E, Noguchi S, Mizuno Y, Hagiwara Y, Yoshida M. From dystrophinopathy to sarcoglycanopathy: evolution of a concept of muscular dystrophy. Muscle Nerve. 1998 Apr;21(4):421 - 38. doi: 10.1002/(sici)1097-4598(199804)21:4<421::aid-mus1>3.0.co;2-b. PMID: 9533777.

3. Murphy AP, Straub V. The Classification, Natural History and Treatment of the Limb Girdle Muscular Dystrophies. J Neuromuscul Dis. 2015 Jul 22;2(s2):S7-S19. doi: 10.3233/JND-150105. PMID: 27858764; PMCID: PMC5271430.

4. Bönnemann CG, Passos-Bueno MR, McNally EM, Vainzof M, de Sá Moreira E, Marie SK, Pavanello RC, Noguchi S, Ozawa E, Zatz M, Kunkel LM. Genomic screening for beta-sarcoglycan gene mutations: missense mutations may cause severe limb-girdle muscular dystrophy type 2E (LGMDR4). Hum Mol Genet. 1996 Dec;5(12):1953-61. doi: 10.1093/hmg/5.12.1953. PMID: 8968749.

5. Shi W, Chen Z, Schottenfeld J, Stahl RC, Kunkel LM, Chan YM. Specific assembly pathway of sarcoglycans is dependent on beta- and delta-sarcoglycan. Muscle Nerve. 2004 Mar;29(3):409 - 19. doi: 10.1002/mus.10566. PMID: 14981741.

6. Thompson R, Straub V. Limb-girdle muscular dystrophies - international collaborations for translational research. Nat Rev Neurol. 2016 May;12(5):294-309. doi: 10.1038/nrneurol.2016.35. Epub 2016 Apr 1. PMID: 27033376.

7. Schade van Westrum SM, Dekker LR, de Voogt WG, Wilde AA, Ginjaar IB, de Visser M, van der Kooi AJ. Cardiac involvement in Dutch patients with sarcoglycanopathy: a cross-sectional cohort and follow-up study. Muscle Nerve. 2014 Dec;50(6):909 - 13. doi: 10.1002/mus.24233. PMID: 24619517.

8. Petri H, Sveen ML, Thune JJ, Vissing C, Dahlqvist JR, Witting N, Bundgaard H, Køber L, Vissing J. Progression of cardiac involvement in patients with limb-girdle type 2 and Becker muscular dystrophies: a 9-year follow-up study. Int J Cardiol. 2015 Mar 1;182:403 - 11. doi: 10.1016/j.ijcard.2014.12.090. Epub 2014 Dec 27. PMID: 25596466.

9. Fanin M, Melacini P, Boito C, Pegoraro E, Angelini C. LGMD2E patients risk developing dilated cardiomyopathy. Neuromuscul Disord. 2003 May;13(4):303-9. doi: 10.1016/s0960-8966(02)00280-8. PMID: 12868499.

10. Politano L, Nigro V, Passamano L, Petretta V, Comi LI, Papparella S, Nigro G, Rambaldi PF, Raia P, Pini A, Mora M, Giugliano MA, Esposito MG, Nigro G. Evaluation of cardiac and respiratory involvement in sarcoglycanopathies. Neuromuscul Disord. 2001 Mar;11(2):178 - 85. doi: 10.1016/s0960-8966(00)00174-7. PMID: 11257475.

11. Simonds AK, Muntoni F, Heather S, Fielding S. Impact of nasal ventilation on survival in hypercapnic Duchenne muscular dystrophy. Thorax. 1998 Nov;53(11):949-52. doi:10.1136/thx.53.11.949. PMID: 10193393; PMCID: PMC1745110.

Page $7 / 12$ 
12. Magri F, Nigro V, Angelini C, Mongini T, Mora M, Moroni I, Toscano A, D'angelo MG, Tomelleri G, Siciliano G, Ricci G, Bruno C, Corti S, Musumeci O, Tasca G, Ricci E, Monforte M, Sciacco M, Fiorillo C, Gandossini S, Minetti C, Morandi L, Savarese M, Fruscio GD, Semplicini C, Pegoraro E, Govoni A, Brusa R, Del Bo R, Ronchi D, Moggio M, Bresolin N, Comi GP. The italian limb girdle muscular dystrophy registry: Relative frequency, clinical features, and differential diagnosis. Muscle Nerve. 2017 Jan;55(1):55-68. doi:10.1002/mus.25192. Epub 2016 Oct 28. PMID: 27184587.

13. Fayssoil A, Ogna A, Chaffaut C, Chevret S, Guimarães-Costa R, Leturcq F, Wahbi K, Prigent H, Lofaso F, Nardi O, Clair B, Behin A, Stojkovic T, Laforet P, Orlikowski D, Annane D. Natural History of Cardiac and Respiratory Involvement, Prognosis and Predictive Factors for LongTerm Survival in Adult Patients with Limb Girdle Muscular Dystrophies Type 2C and 2D. PLoS One. 2016 Apr 27;11(4):e0153095. doi: 10.1371/journal.pone.0153095. PMID: 27120200; PMCID: PMC4847860.

14. Marsolier J, Laforet P, Pegoraro E, Vissing J, Richard I, Sarcoglycanopathies. Working Group. 1st International Workshop on Clinical trial readiness for sarcoglycanopathies 15-16 November 2016, Evry, France. Neuromuscul Disord. 2017 Jul;27(7):683-692. doi: 10.1016/j.nmd.2017.02.011. Epub 2017 Mar 3. PMID: 28521973.

15. Alonso-Pérez J, González-Quereda L, Bello L, Guglieri M, Straub V, Gallano P, Semplicini C, Pegoraro E, Zangaro V, Nascimento A, Ortez C, Comi GP, Dam LT, De Visser M, van der Kooi AJ, Garrido C, Santos M, Schara U, Gangfuß A, Løkken N, Storgaard JH, Vissing J, Schoser B, Dekomien G, Udd B, Palmio J, D'Amico A, Politano L, Nigro V, Bruno C, Panicucci C, Sarkozy A, Abdel-Mannan O, Alonso-Jimenez A, Claeys KG, Gomez-Andrés D, Munell F, Costa-Comellas L, Haberlová J, Rohlenová M, Elke V, De Bleecker JL, Dominguez-González C, Tasca G, Weiss C, Deconinck N, Fernández-Torrón R, López de Munain A, Camacho-Salas A, Melegh B, Hadzsiev K, Leonardis L, Koritnik B, Garibaldi M, de Leon-Hernández JC, Malfatti E, Fraga-Bau A, Richard I, Illa I, Díaz-Manera J. New genotype-phenotype correlations in a large European cohort of patients with sarcoglycanopathy. Brain. 2020 Sep 1;143(9):2696-2708. doi: 10.1093/brain/awaa228. PMID: 32875335 .

16. Melacini P, Fanin M, Duggan DJ, Freda MP, Berardinelli A, Danieli GA, Barchitta A, Hoffman EP, Dalla Volta S, Angelini C. Heart involvement in muscular dystrophies due to sarcoglycan gene mutations. Muscle Nerve. 1999 Apr;22(4):473-9. doi: 10.1002/(sici)10974598(199904)22:4<473::aid-mus8>3.0.c0;2-5. PMID: 10204782.

17. Winckler PB, da Silva AMS, Coimbra-Neto AR, Carvalho E, Cavalcanti EBU, Sobreira CFR, Marrone CD, Machado-Costa MC, Carvalho AAS, Feio RHF, Rodrigues CL, Gonçalves MVM, Tenório RB, Mendonça RH, Cotta A, Paim JFO, Costa E, Silva C, de Aquino Cruz C, Bená MI, Betancur DFA, El Husny AS, de Souza ICN, Duarte RCB, Reed UC, Chaves MLF, Zanoteli E, França MC Jr, Saute JA. Clinicogenetic lessons from 370 patients with autosomal recessive limb-girdle muscular dystrophy. Clin Genet. 2019 0ct;96(4):341-53. doi:10.1111/cge.13597. Epub 2019 Jul 15. PMID: 31268554.

18. Semplicini C, Vissing J, Dahlqvist JR, Stojkovic T, Bello L, Witting N, Duno M, Leturcq F, Bertolin C, D'Ambrosio P, Eymard B, Angelini C, Politano L, Laforêt P, Pegoraro E. Clinical and genetic spectrum in limb-girdle muscular dystrophy type 2E. Neurology. 2015 Apr 28;84(17):1772-81. doi: 10.1212/WNL.0000000000001519. Epub 2015 Apr 10. PMID: 25862795; PMCID: PMC4424130.

19. Mayer $\mathrm{OH}$, Finkel RS, Rummey C, Benton MJ, Glanzman AM, Flickinger J, Lindström BM, Meier T. Characterization of pulmonary function in Duchenne Muscular Dystrophy. Pediatr Pulmonol. 2015 May;50(5):487-94. doi:10.1002/ppul.23172. Epub 2015 Mar 9. PMID: 25755201; PMCID: PMC4402127.

20. Meier T, Rummey C, Leinonen M, Spagnolo P, Mayer OH, Buyse GM. DELOS Study Group. Characterization of pulmonary function in 1018 year old patients with Duchenne muscular dystrophy. Neuromuscul Disord. 2017 Apr;27(4):307-314. doi: 10.1016/j.nmd.2016.12.014. Epub 2017 Jan 6. PMID: 28189481.

21. McDonald CM, Abresch RT, Carter GT, Fowler WM Jr, Johnson ER, Kilmer DD, Sigford BJ. Profiles of neuromuscular diseases. Duchenne muscular dystrophy. Am J Phys Med Rehabil. 1995 Sep-Oct;74(5 Suppl):S70-92. doi: 10.1097/00002060-199509001-00003. PMID: 7576424.

22. Gochicoa-Rangel L, Vargas-Domínguez C, García-Mujica ME, Bautista-Bernal A, Salas-Escamilla I, Pérez-Padilla R, Torre-Bouscoulet L. Quality of spirometry in 5-to-8-year-old children. Pediatr Pulmonol. 2013 Dec;48(12):1231-6. doi:10.1002/ppul.22765. Epub 2013 Feb 8. PMID: 23401425.

23. Phillips MF, Quinlivan RC, Edwards RH, Calverley PM. Changes in spirometry over time as a prognostic marker in patients with Duchenne muscular dystrophy. Am J Respir Crit Care Med. 2001 Dec 15;164(12):2191-4. doi: 10.1164/ajrccm.164.12.2103052. PMID: 11751186.

\section{Tables}


Table 1

Evolution of clinical features with ageing in LGMDR4, as estimated by univariate generalized linear regression. Multivariate linear regression models (three alternative models, considering different combinations of variables) were considered to examine to more robust independent

biomarkers of disease progression. Multivariate model 1 was adjusted for 42 observations, multivariate model 2 was adjusted for 25

observations and multivariate model 3 was adjusted for 21 observations.

\begin{tabular}{|c|c|c|c|c|c|c|c|c|c|c|c|c|}
\hline & \multicolumn{3}{|c|}{ UNIVARIATE } & \multicolumn{3}{|c|}{ MULTIVARIATE MODEL 1} & \multicolumn{3}{|c|}{ MULTIVARIATE MODEL 2} & \multicolumn{3}{|c|}{ MULTIVARIATE MODEL 3} \\
\hline & Estimate & $\begin{array}{l}\text { Std } \\
\text { Error }\end{array}$ & $P$ value & Estimate & $\begin{array}{l}\text { Std } \\
\text { Error }\end{array}$ & $P$ value & Estimate & $\begin{array}{l}\text { Std } \\
\text { Error }\end{array}$ & $P$ value & Estimate & $\begin{array}{l}\text { Std } \\
\text { Error }\end{array}$ & $P$ value \\
\hline $\begin{array}{l}\text { CPK, } \\
\text { IU/L } \\
(n= \\
114)\end{array}$ & $\begin{array}{l}-6,59 \mathrm{E}- \\
04\end{array}$ & $\begin{array}{l}9,87 \mathrm{E}- \\
05\end{array}$ & $\begin{array}{l}8,30 \mathrm{E}- \\
10 *\end{array}$ & $-4,15 E-5$ & $\begin{array}{l}4,39 E- \\
04\end{array}$ & 0,92 & $\begin{array}{l}-7,71 \mathrm{E}- \\
04\end{array}$ & $\begin{array}{l}4,31 E- \\
04\end{array}$ & 0,079 & $2,18 \mathrm{E}-04$ & $\begin{array}{l}5,77 E- \\
04\end{array}$ & 0,71 \\
\hline $\begin{array}{l}E F, \% \\
(n= \\
62)\end{array}$ & $\begin{array}{l}-4,48 E- \\
01\end{array}$ & $\begin{array}{l}1,41 \mathrm{E}- \\
01\end{array}$ & $0,0023^{*}$ & $\begin{array}{l}-0,27 E- \\
01\end{array}$ & $\begin{array}{l}7,89 E- \\
02\end{array}$ & $0,0019 *$ & & & & $\begin{array}{l}-2,80 \mathrm{E}- \\
01\end{array}$ & $\begin{array}{l}1,13 E- \\
01\end{array}$ & $0,0201 *$ \\
\hline $\begin{array}{l}\text { VC, \% } \\
(n= \\
52)\end{array}$ & $\begin{array}{l}-7,45 \mathrm{E}- \\
02\end{array}$ & $\begin{array}{l}1,89 \mathrm{E}- \\
02\end{array}$ & $0,0002 *$ & & & & & & & & & \\
\hline $\begin{array}{l}\text { FVC, } \\
\% \\
(n= \\
51)\end{array}$ & $\begin{array}{l}-1,75 \mathrm{E}- \\
01\end{array}$ & $\begin{array}{l}3,31 \mathrm{E}- \\
02\end{array}$ & $\begin{array}{l}2,42 E- \\
06 *\end{array}$ & & & & & & & & & \\
\hline $\begin{array}{l}\text { FEV1, } \\
\% \\
(\mathrm{n}= \\
62)\end{array}$ & $\begin{array}{l}-1,86 \mathrm{E}- \\
01\end{array}$ & $\begin{array}{l}2,77 \mathrm{E}- \\
02\end{array}$ & $\begin{array}{l}5,96 \mathrm{E}- \\
09 *\end{array}$ & & & & $\begin{array}{l}-1,28 \mathrm{E}- \\
01\end{array}$ & $\begin{array}{l}3,92 E- \\
02\end{array}$ & $0,0021 *$ & $\begin{array}{l}-5,30 \mathrm{E}- \\
01\end{array}$ & $\begin{array}{l}5,45 E- \\
01\end{array}$ & 0,34 \\
\hline \multicolumn{13}{|c|}{$\begin{array}{l}\text { CPK = Creatine Phospokinase, EF= ejection fraction, } \mathrm{VC}=\text { Vital Capacity, considered as percentage of predicted, FVC= Forced Vital } \\
\text { Capacity, considered as percentage of predicted, FEV1 = Forced Expiratory Volume in the first second considered as percentage of } \\
\text { predicted. }\end{array}$} \\
\hline$N=n$ & er of obs & ations & orded. & & & & & & & & & \\
\hline
\end{tabular}

Table 2

Evolution of clinical features with ageing in LGMDR4 Groups A and B, as estimated by univariate generalized linear regression.

\begin{tabular}{|c|c|c|c|c|c|c|c|c|c|c|}
\hline & \multicolumn{5}{|c|}{ UNIVARIATE GROUP A } & \multicolumn{5}{|c|}{ UNIVARIATE GROUP B } \\
\hline & $\mathrm{N}$ & Line regression & Estimate & Std Error & $P$ value & $\mathrm{N}$ & Line regression & Estimate & Std Error & $P$ value \\
\hline $\begin{array}{l}\text { CPK, } \\
\text { IU/L }\end{array}$ & 70 & $\begin{array}{l}15069,72- \\
907,52\end{array}$ & $\begin{array}{l}-9,08 \mathrm{E}+ \\
02\end{array}$ & $\begin{array}{l}9,97 \mathrm{E}+ \\
01\end{array}$ & $2 \mathrm{E}-13^{*}$ & 43 & $\begin{array}{l}10770,49- \\
344,96\end{array}$ & $\begin{array}{l}-3,45 E+ \\
02\end{array}$ & $\begin{array}{l}8,69 \mathrm{E}+ \\
01\end{array}$ & $\begin{array}{l}2,80 \mathrm{E}- \\
04^{*}\end{array}$ \\
\hline$E F, \%$ & 28 & $67,28-0,99$ & $-0,99$ & 0,44 & $\begin{array}{l}3,40 E- \\
02^{*}\end{array}$ & 34 & $63,84-0,39$ & $-0,39$ & 0,11 & $1,2 \mathrm{E}-3 *$ \\
\hline VC, \% & 41 & $124,03-3,56$ & $-3,56$ & 1,08 & $2,1 \mathrm{E}-3^{*}$ & 11 & $95,75-1,85$ & $-1,85$ & 0,15 & $5,7 \mathrm{E}-7 *$ \\
\hline FVC, \% & 37 & $110,49-3,56$ & $-3,56$ & 0.42 & $\begin{array}{l}5,01 \mathrm{E}- \\
10^{\star}\end{array}$ & 14 & $71,49-1,12$ & $-1,12$ & 0,82 & 0.20 \\
\hline FEV1, \% & 45 & $112,76-3,55$ & $-3,55$ & 0,44 & $3 \mathrm{E}-10 *$ & 17 & $90,98-1,64$ & $-1,64$ & 0,57 & $0.01 *$ \\
\hline \multicolumn{11}{|c|}{$\begin{array}{l}\mathrm{CPK}=\text { Creatine Phospokinase, } \mathrm{EF}=\text { ejection fraction, } \mathrm{VC}=\text { Vital Capacity, considered as percentage of predicted, FVC= Forced Vital } \\
\text { Capacity, considered as percentage of predicted, FEV } 1=\text { Forced Expiratory Volume in the first second considered as percentage of } \\
\text { predicted. }\end{array}$} \\
\hline
\end{tabular}


Table 3

study of possible correlation between variables. Each variable was related to all other variables under study.

\begin{tabular}{|c|c|c|c|c|}
\hline Variable 1 & Variable 2 & Correlation & $\mathbf{N}$ & $P$ value \\
\hline CPK, UI/L & Age & $-0,53$ & 114 & $1,30 \mathrm{E}-09 *$ \\
\hline$E F, \%$ & Age & $-0,37$ & 62 & 2,80E-03* \\
\hline$E F, \%$ & CPK, UI/L & 0,11 & 25 & 5,90E-01 \\
\hline VC, \% & Age & $-0,48$ & 52 & $3,20 \mathrm{E}-04^{*}$ \\
\hline VC, \% & CPK, UI/L & 0,35 & 35 & $4,10 \mathrm{E}-02 *$ \\
\hline VC, \% & $E F, \%$ & 0,56 & 25 & $3,40 \mathrm{E}-03 *$ \\
\hline FVC, \% & Age & $-0,59$ & 51 & $4,20 \mathrm{E}-06 *$ \\
\hline FVC, \% & CPK, UI/L & 0,47 & 36 & $3,80 \mathrm{E}-03 *$ \\
\hline FVC, \% & $E F, \%$ & 0,62 & 28 & $4,10 \mathrm{E}-04^{*}$ \\
\hline FVC, \% & VC, \% & 0,36 & 29 & 5,80E-02 \\
\hline FEV1, \% & Age & $-0,65$ & 62 & $1,20 \mathrm{E}-08 *$ \\
\hline FEV1, \% & CPK, UI/L & 0,52 & 42 & $4,70 \mathrm{E}-04^{\star}$ \\
\hline FEV1, \% & $E F, \%$ & 0,49 & 30 & $5,90 \mathrm{E}-03 *$ \\
\hline FEV1, \% & VC, \% & 0,42 & 39 & $8,60 \mathrm{E}-03 *$ \\
\hline FEV1, \% & FVC, \% & 0,95 & 48 & $7,00 \mathrm{E}-26 *$ \\
\hline \multicolumn{5}{|c|}{$\begin{array}{l}\text { CPK = Creatine Phosphokinase, } \mathrm{EF}=\text { ejection fraction, } \mathrm{VC}=\text { Vital Capacity, considered as percentage of predicted, } \mathrm{FVC}=\mathrm{Forced} \mathrm{Vital} \\
\text { Capacity, considered as percentage of predicted, FEV1 = Forced Expiratory Volume in the first second considered as percentage of } \\
\text { predicted. }\end{array}$} \\
\hline \multicolumn{5}{|c|}{$\mathrm{N}=$ number of observations recorded. } \\
\hline
\end{tabular}

\section{Figures}




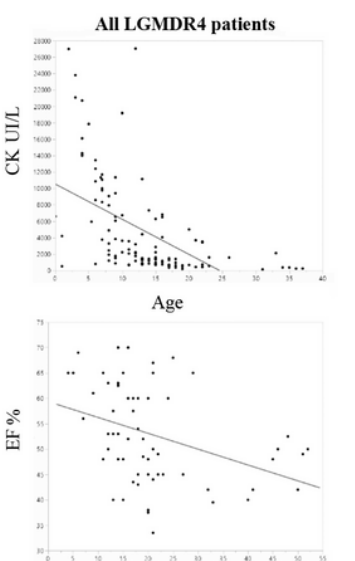

Age

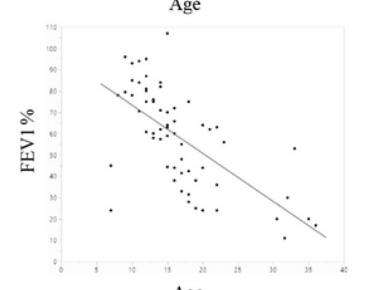

Age

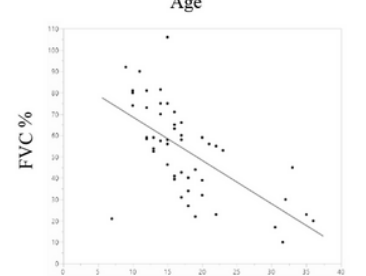

Age

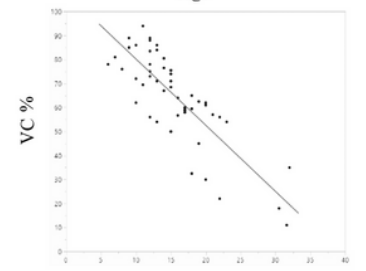

Age

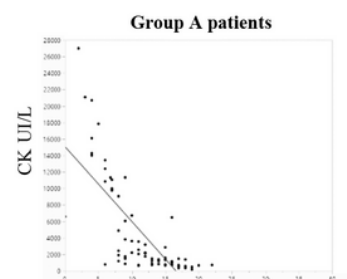

Age

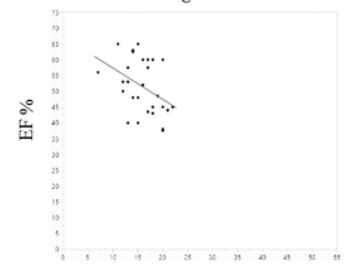

Age

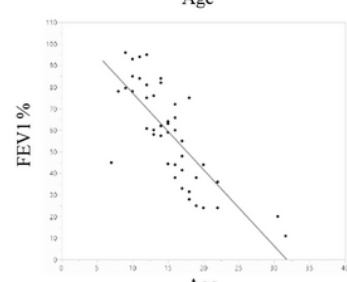

Age

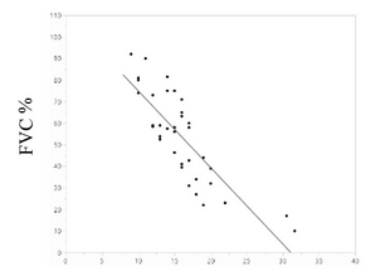

Age

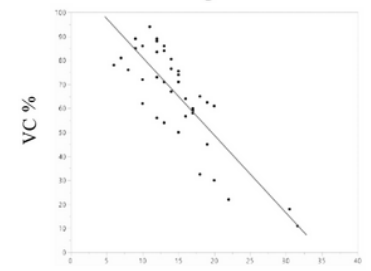

Age

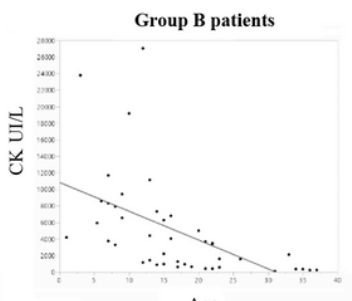

Age

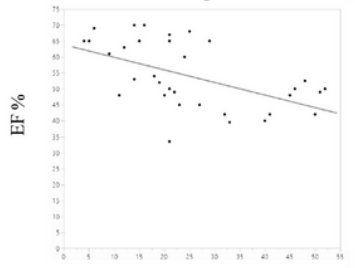

Age
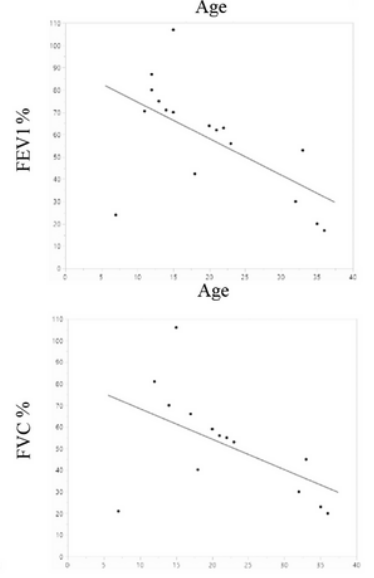

Age

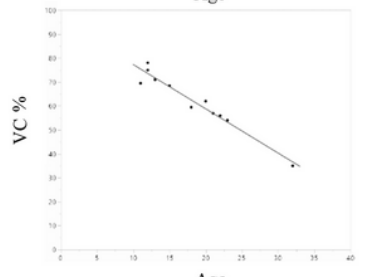

Age

Figure 1

All graphics were created using JMP by SAS. First line: evolution of CPK in all patients and in group A and B over years: on $Y$ axe CPK values expressed in $\mathrm{UI} / \mathrm{L}$, on $\mathrm{X}$ axe age expressed in years ( $p$ value 8,3e-10 total patients, $p=2 \mathrm{E}-13$ group $A$ and $p=2,80 \mathrm{E}-04$ group $B$ ). Second line: evolution of $\mathrm{EF}$ in all patients and in group $\mathrm{A}$ and $\mathrm{B}$ over years: on $\mathrm{Y}$ axe $\mathrm{EF}$ values expressed as percentage, on $\mathrm{X}$ axe age expressed in years ( $p$ value 0,0023 total patients, $p=3,40 E-02$ group $A$ and $p=1,2 E-3$ group $B$ ). Third line: evolution of FEV1 in all patients and in group $A$ and $B$ over years: on $Y$ axe FEV1 values expressed as percentage, on $X$ axe age expressed in years ( $p$ value 5,96e-9 total patients, $p=3 E-10$ group A and $p=0.01^{*}$ group $B$ ). Fourth line: evolution of $F V C$ in all patients and in group $A$ and $B$ over years: on $Y$ axe FVC values expressed as percentage of predicted value, on $X$ axe age expressed in years ( $p$ value 2,42e-6 total patients, $p=5,01 \mathrm{E}-10$ group $A$ and $p=0.20$ group $B$ ). Fifth line: evolution of $\mathrm{VC}$ in all patients and in group $\mathrm{A}$ and $\mathrm{B}$ over years: on $\mathrm{Y}$ axe $\mathrm{VC}$ values expressed as percentage of predicted value, on $X$ axe age expressed in years $\left(p=0,0002\right.$ total patients, $p=2,1 E-3$ group $A$ and $p=5,7 E-7^{*}$ group $\left.B\right)$. 


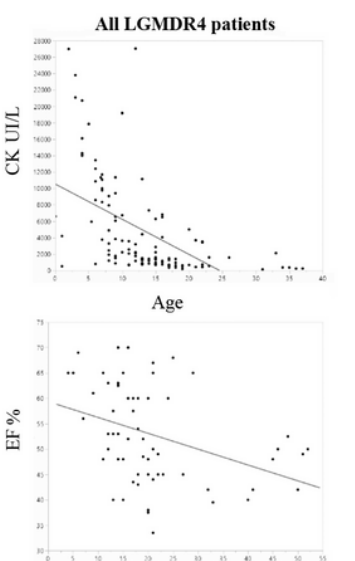

Age

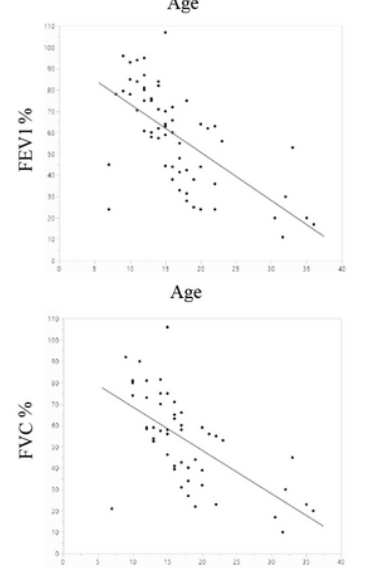

Age

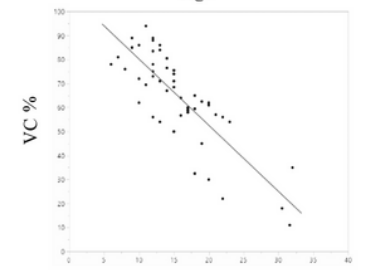

Age

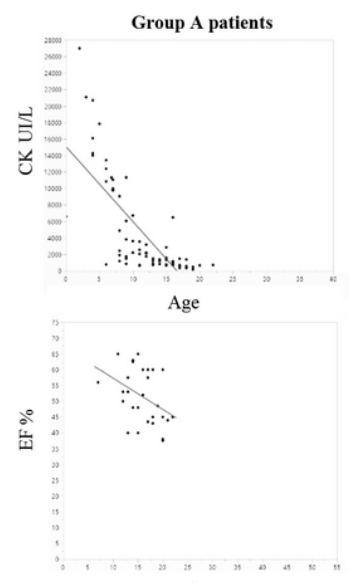

Age

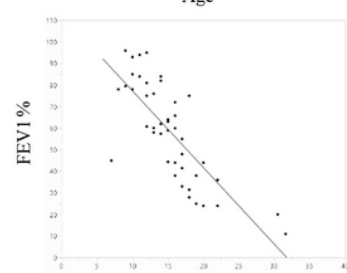

Age

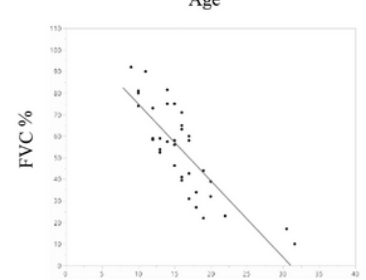

Age

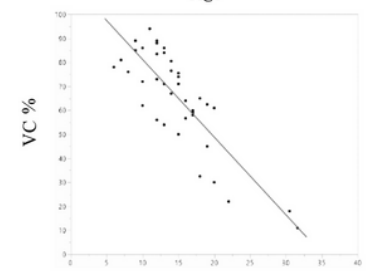

Age

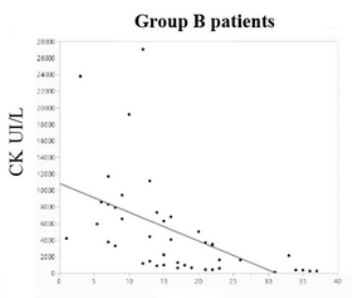

Age

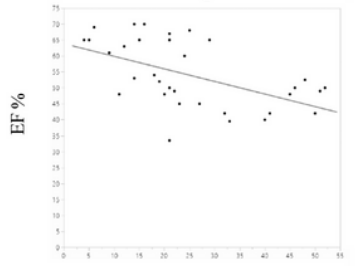

Age
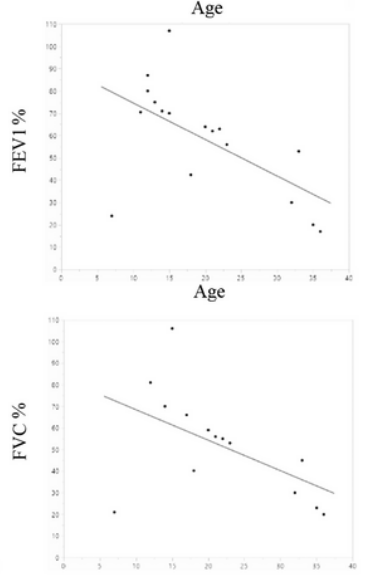

Age

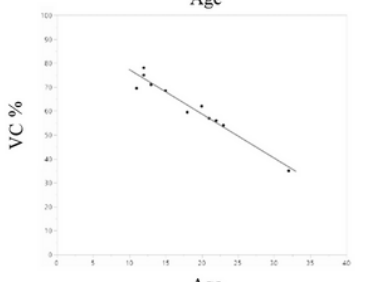

Age

Figure 1

All graphics were created using JMP by SAS. First line: evolution of CPK in all patients and in group A and B over years: on $Y$ axe CPK values expressed in $\mathrm{UI} / \mathrm{L}$, on $\mathrm{X}$ axe age expressed in years ( $p$ value 8,3e-10 total patients, $p=2 \mathrm{E}-13$ group $A$ and $p=2,80 \mathrm{E}-04$ group $B$ ). Second line: evolution of $\mathrm{EF}$ in all patients and in group $\mathrm{A}$ and $\mathrm{B}$ over years: on $\mathrm{Y}$ axe $\mathrm{EF}$ values expressed as percentage, on $\mathrm{X}$ axe age expressed in years ( $p$ value 0,0023 total patients, $p=3,40 E-02$ group $A$ and $p=1,2 E-3$ group $B$ ). Third line: evolution of FEV1 in all patients and in group $A$ and $B$ over years: on $Y$ axe FEV1 values expressed as percentage, on $X$ axe age expressed in years ( $p$ value 5,96e-9 total patients, $p=3 E-10$ group $A$ and $p=0.01^{*}$ group $B$ ). Fourth line: evolution of FVC in all patients and in group $A$ and $B$ over years: on $Y$ axe FVC values expressed as percentage of predicted value, on $X$ axe age expressed in years ( $p$ value 2,42e-6 total patients, $p=5,01 \mathrm{E}-10$ group $A$ and $p=0.20$ group $B$ ). Fifth line: evolution of $\mathrm{VC}$ in all patients and in group $\mathrm{A}$ and $\mathrm{B}$ over years: on $\mathrm{Y}$ axe $\mathrm{VC}$ values expressed as percentage of predicted value, on $X$ axe age expressed in years $\left(p=0,0002\right.$ total patients, $p=2,1 E-3$ group $A$ and $p=5,7 E-7^{*}$ group $\left.B\right)$.

\section{Supplementary Files}

This is a list of supplementary files associated with this preprint. Click to download.

- SupplementaryTable1.docx

- SupplementaryTable1.docx 